\title{
A Review of Decentralized Assembly Systems
}

\begin{abstract}
This review classifies the existing studies on decentralized assembly systems into two branches. The first branch focuses on equilibrium decisions. The other branch pays attention to the coordination mechanism. This paper enables readers to get the knowledge of research status of decentralized assembly systems. Directions of future research are also discussed in this paper.
\end{abstract}

FU Hong, MA Yong-kai, LIU Yang

School of Management and Economics, University of Electronic Science and Technology of China, Chengdu, China

Keywords: assembly systems; game theory; decentralization

\section{Introduction}

In an assembly system, there are multiple complementary suppliers sell their components to an assembler and then the assembler assembles these components into a final product (Cheng et al. 2012). The assembly system is not very complex, it can be viewed as a special multiple-suppliers-one-retailer supply chain, where components sold by suppliers are complementary.

In a centralized assembly system, there is only one decision maker who decides to maximize the profit of the entire system. Ghosh and Gagnon (1989) review the literature on centralized system. However, the centralized system ignores the interaction among all players. In a decentralized assembly system (hereafter referred as DAS), all players are independent decision makers and have their own interests. Two topics are interesting in DAS.

The first one is equilibrium decisions, such as capacity, inventory, pricing and quantity. Because the double margin (Spengler 1950) exists in DAS, the total profit of players in DAS is less than that of centralized setting. The other interesting topic is the coordination of DAS.

\section{Equilibrium decisions}

The existing studies on equilibrium decisions are divided into two categories based on whether suppliers are allowed to form coalitions or not.

\subsection{Non-cooperative game theory}

By using non-cooperative game 
theory, the existing studies assume that each player can not form a coalition with all other players. There are many papers considering the equilibrium decisions in DAS with insensitive demand. Wang and Gerchak (2003) analyze capacity decisions in both push and pull systems when components are perfectly complementary (the terms "push" and "pull" are adopted from Cachon 2004). Bernstein and DeCroix (2004) extended Wang and Gerchak's (2003) pull model into multitier assembly systems in which each subassembler supplier of a module has its own suppliers. Bernstein et al. (2007) study capacity decisions in DAS in which two final products are assembled from three components. Bernstein et al. (2011) investigate the impact of postponing the allocation decision on capacity. Fang (2012) explore the capacity games for partially complementary components. Bernstein and DeCroix (2006) consider inventory decisions in DAS. All the above studies assume that assembler has only one chance to order the components from suppliers to meet the uncertain demand. Fang et al. (2008) investigate inventory decisions in DAS and allow for multiple deliveries. Kalkancı and Erhun (2012) analyze pricing in DAS. Moreover, Du et al. (2014) quantify the efficiency of DAS.

As for DAS with sensitive demand, Wang (2006) studies the pricing and production decisions. In his model, the assembler first chooses its revenue share and then suppliers choose their pricing and production quantities. Jiang and Wang (2010) explore pricing and production decisions, and allow for direct competition a supplier faces.

\subsection{Mixture game theory}

With a mixture of non-cooperative and cooperative game theory, the existing studies assume that all suppliers can form coalitions with each other, but suppliers can not form coalitions with the assembler.

The first branch assumes that the demand is price insensitive. Granot and Yin (2008) study supplier coalitions in both push and pull systems with uncertain demand. They find that coalition is easier to reach in a pull system than a push model, and in the push setting whether the component suppliers will form a grand coalition depends on their perspective of future defections. Nagarajan and Bassok (2008) find that no coalition emerges if the assembler's bargaining power is strong.

The other branch assumes that the demand is price sensitive. Nagarajan and Sošić (2009) and Nagarajan and Sošić (2011) study supplier coalition in DAS with price-sensitive deterministic demand. Sošić (2011) study the impact of demand uncertainty on supplier coalition in DAS with price-sensitive and uncertain demand; and find that when the ordering quantity can be determined after observing the true demand, the coalition stability of suppliers 
is not impacted by demand uncertainty. Yin (2010) investigates how demand conditions drive coalition formation among suppliers.

\section{Coordination mechanism}

The studies on coordination of DAS aim at eliminating the double margin and achieve Pareto improvement. Gerchak and Wang (2004) are the first to investigate coordination of DAS. They find that the push system can be coordinated by using buy-back policy, and the pull system can be coordinated by using a revenue-plus-surplus-subsidy incentive scheme. Zou et al. (2008) extend the model of Gerchak and Wang (2004) to the two-period setting. Gurnani and Gerchak (2007) and Yan et al. (2010) study the coordination of DAS and allow for random yield. Güler and Bilgic (2009) investigate the coordination of DAS in which the demand and the yield are both random. Zhang et al. (2008) explore the coordination of DAS with two configurations. Zou et al. (2004) deal with the coordination of DAS, and allow for synchronized processing time and delivery quantity. Yang et al. (2011) investigate the coordination of DAS consisting of one assembler and two complementary component suppliers with different lead-times. Xiao and Shen (2011) study the coordination of DAS with a key supplier and multiple non-key suppliers.
All the above studies on coordination mechanism assume that the demand is price insensitive.

\section{Concluding remarks}

Though there are many studies on DAS, few studies summarize and classify these studies. This paper classifies them into two broad categories: equilibrium decisions and coordination. There are many opportunities for further development of literature on DAS: (1) allow exchange risk in DAS; (2) investigate the coordination of DAS with uncertain and price sensitive demand.

5.Acknowledgments: We would like to acknowledge the financial support from National Natural Sciences Foundation of china (70932005) and Doctoral Programs Foundation of Ministry of Education of China (20100175110017).

\section{References}

[1] F. Bernstein, G. DeCroix, "Decentralized Pricing and Capacity Decisions in a Multitier System with Modular Assembly," Management Sci., 50(9), pp. 1293-1308, 2004.

[2] F. Bernstein, G. DeCroix, "Inventory Policies in a Decentralized Assembly System," Oper. Res., 54(2), pp. 324-336, 2006.

[3] F. Bernstein, G. DeCroix, Y. Wang, "Incentives and Commonality in a Decentralized Multiproduct Assembly 
System," Oper. Res., 55(4), pp. 630-646, 2007.

[4] F. Bernstein, G. DeCroix, Y. Wang, "The Impact of Demand Aggregation Through Delayed Component Allocation in an Assemble-to-Order System," Management Sci., 57(6), pp. 1154-1171, 2011.

[5] G. Cachon, "The Allocation of Inventory Risk in a Supply Chain: Push, Pull, and Advance-Purchase Discount Contracts," Management Sci., 50(2), pp. 222-238, 2004.

[6] F. Cheng, M. Ettl, Y. Lu, D. Yao, “A Production-Inventory Model for a Push-Pull Manufacturing System with Capacity and Service Level Constraints," Production Oper. Management, 21(4), pp. 668-681, 2012.

[7] D. Du, B. Chen, D. Xu, "Quantifying The Efficiency of Price-Only Contracts in Push Supply Chains Over Demand Distributions of Known Supports," Omega, 42(1), pp. 98-108, 2014.

[8] X. Fang, "Capacity Games for Partially Complementary Products Under Multivariate Random Demands," Nav. Res. Log., 59(2), pp. 146-159, 2012.

[9] X. Fang, K. So, Y. Wang, “ Component Procurement Strategies in Decentralized Assemble-to-Order Systems with Time-Dependent Pricing," Management Sci., 54(12), pp.
1997-2011, 2008.

[10] Y. Gerchak, Y. Wang, "Revenue-Sharing vs. Wholesale-Price Contracts in Assembly Systems with Random Demand." Production Oper. Management, 13(1), pp. 23-33, 2004.

[11] S. Ghosh, R. Gagnon, “A Comprehensive Literature Review and Analysis of The Design, Balancing and Scheduling of Assembly Systems," Int. J. Prod. Res., 27(4), pp. 637-670, 1989.

[12] D. Granot, S. Yin, "Competition and Cooperation in Decentralized Push and Pull Assembly Systems," Management Sci., 54(4), pp. 733-747, 2008

[13] H. Gurnania, Y. Gerchak, "Coordination in Decentralized Assembly Systems with Uncertain Component Yields," Eur. J. Oper. Res., 176(3), pp. 1559-1576, 2007.

[14] M. Güler, T. Bilgic, "On Coordinating an Assembly System Under Random Yield and Random Demand," Eur. J. Oper. Res., 196(1), pp. 342-350, 2009.

[15] L. Jiang, Y. Wang, "Supplier Competition in Decentralized Assembly Systems with Price-Sensitive and Uncertain Demand," Manufacturing Service Oper. Management, 12(1), pp. 93-101, 2010.

[16] B. Kalkanc1, F. Erhun, "Pricing 
Games and Impact of Private Demand Information in Decentralized Assembly Systems," Oper. Res., 60(5), pp. 1142-1156, 2012.

[17] M. Nagarajan, Y. Bassok, "A Bargaining Framework in Supply Chains: The Assembly Problem," Management Sci., 54(8), pp. 1482-1496, 2008.

[18] M. Nagarajan, G. Sošić, "Coalition Stability in Assembly Models," Oper. Res., 57(1), pp. 131-145, 2009.

[19] M. Nagarajan, G. Sošić, "Stable Supplier Coalitions in Assembly Systems with Commodity Components," Working Paper, 2011.

[20] J. Spengler, "Vertical Integration and Antitrust Policy," J. of Political Economy, 58(4), pp. 347-352, 1950.

[21] G. Sošić, "Impact of Demand Uncertainty on Stability of Supplier Alliances in Assembly Models," Production Oper. Management, 20(6), pp. 905-920, 2011.

[22] Y. Wang, Y. Gerchak, "Capacity Games in Assembly Systems with Uncertain Demand," Manufacturing Service Oper. Management, 50(3), pp. 252-267, 2003.

[23] Y. Wang, "Joint Pricing-Production Decisions in Supply Chains of Complementary Products with Uncertain Demand". Oper. Res., 54(6), pp. 1110-1127, 2006.

[24] T. Xiao, H. Shen, "Study on Coordination of Capacity Reservation under Asymmetric Information," $J$. System Sci. Mathematical Sci., 31(10), pp. 1232-1240, 2011.

[25] X. Yan, M. Zhang, K. Liu, “A Note on Coordination in Decentralized Assembly Systems with Uncertain Component Yields," Eur. J. Oper. Res., 205(2), pp. 469-478, 2010.

[26] D. Yang, T. Choi, T. Xiao, T. Cheng, "Coordinating a Two-Supplier and One-Retailer Supply Chain with Forecast Updating," Automatica, 47(7), pp. 1317-1329, 2011.

[27] S. Yin, "Alliance formation among perfectly complementary suppliers in a price-sensitive assembly system," Manufacturing Service Oper. Management, 12(3), pp. 527-544, 2010

[28] X. Zhang, J. Ou, S. Gilbert, "Coordination of Stocking Decisions in an Assemble-to-Order Environment," Eur. J. Oper. Res., 189(2), pp. 540-558, 2008.

[29] X. Zou, S. Pokharel, R. Piplani, "Channel Coordination in an Assembly System Facing Uncertain Demand with Synchronized Processing Time and Delivery Quantity," Int. J. Prod. Res., 42(22), pp. 4673-4689, 2004.

[30] X. Zou, S. Pokharel, R. Piplani, “A Two-Period Supply Contract Model for a Decentralized Assembly System," Eur. J. Oper. Res., 187(1), pp. 257-274, 2008. 